\title{
Metabolism of Short Chain Fatty Acids in the Colon and Faeces of Mice After a Supplementation of Diets with Agave Fructans
}

\author{
Alicia Huazano-García and Mercedes G. López \\ Additional information is available at the end of the chapter
}

http://dx.doi.org/10.5772/51248

\section{Introduction}

\subsection{Fructans}

Most plants store starch or sucrose as reserve carbohydrates, but approximately $12-15 \%$ of higher plants (representing more than 40,000 species) synthesizes fructans as their main source of carbohydrates [1]. Fructans are found naturally in plants as a heterogeneous mixture of different polymerization degrees, they are a polydisperse mixture. Among plants that store fructans, many are economically important, due to its content of fructans, as it is the case of chicory (Cichorium intybus), agave (Agave spp.), artichoke (Cynara scolymus), dahlia (Dahlia variabilis), garlic (Allium sativum) and wheat (Triticum asetivum) [2,3]. Five different groups of fructans have been found in nature and distinguished according to the type of linkage between fructose units and the position of the glucose moiety within the structure. These groups consist of inulins, neoseries inulins, levans, neoseries levans and graminans. Inulins consist of a linear $\beta(2-1)$ linked fructosyl chain; neoseries inulins are composed of two linear $\beta(2-1)$ linked fructosyl chains, one bound to the fructosyl residue of the sucrose, the other bound to the glucosyl residue of the same sucrose molecule; levans consist a of linear $\beta(2-6)$ linked fructosyl chain; neoseries levans are composed of two linear $\beta(2-6)$ linked fructosyl chains, one bound to the fructosyl residue of the sucrose, the other bound to the glucosyl residue and graminans which present both linkages, $\beta(2-1)$ and $\beta(2-6)$ links to the fructose moiety of sucrose [4].

Currently, inulins are extracted from chicory roots, containing fructose chains having a degree of polymerization (DP) from 3 to 60 [2] (Figure 1a). The chemical or enzymatic (endoinulinases) hydrolysis of inulins produces inulins of shorter DP $(\mathrm{DP}<10)$, these are called fructooligosaccharides (FOS) [5, 6]. 
Mexico is considered the origin center of evolution and diversification of the Agave genus, since a large number of agave species are found in its territory. The Agave genus includes approximately 166 species and is the largest genus among the Agavaceae family that consists of 9 genera and approximately 293 species $[7,8]$. The agave plants have the ability to grow in extremely dry-hot environments, where sometimes this plant is the predominant or exclusive flora in that type of a geo-climatic zone, however, they can also be found in diverse ecosystems, such as productive highlands and elevated humidity [9]. These plants present a crassulacean acid metabolism (CAM) and their principal photosynthetic products are fructans [10], fructans are synthesized and stored in the stems of agave plants. Agave is the most exploited genus and economically important as the raw materials are used on the production of alcoholic beverages such tequila (A. tequilana) and mezcal (A. angustifolia, $A$. potatorum, A. cantala, A. duranguensis, to mention some) in Mexico. A. angustifolia is an endemic plant that grows in different states of Mexico; however the main producing states are Oaxaca and Sonora. Fructans in A. angustifolia from Oaxaca represent more than $85 \%$ of total water soluble carbohydrates in the plant, with an estimated DP of 32 [11].

Agave fructans posses a molecular structure compose of a complex mixture containing highly branched molecules with $\beta(2-1)$ and $\beta(2-6)$ linkages, as well as internal and external glucose units, due to the existence of both types of glucose, agave fructans have been classified as graminans (external glucose) and agavins (internal glucose) [11] (Figure 1b).
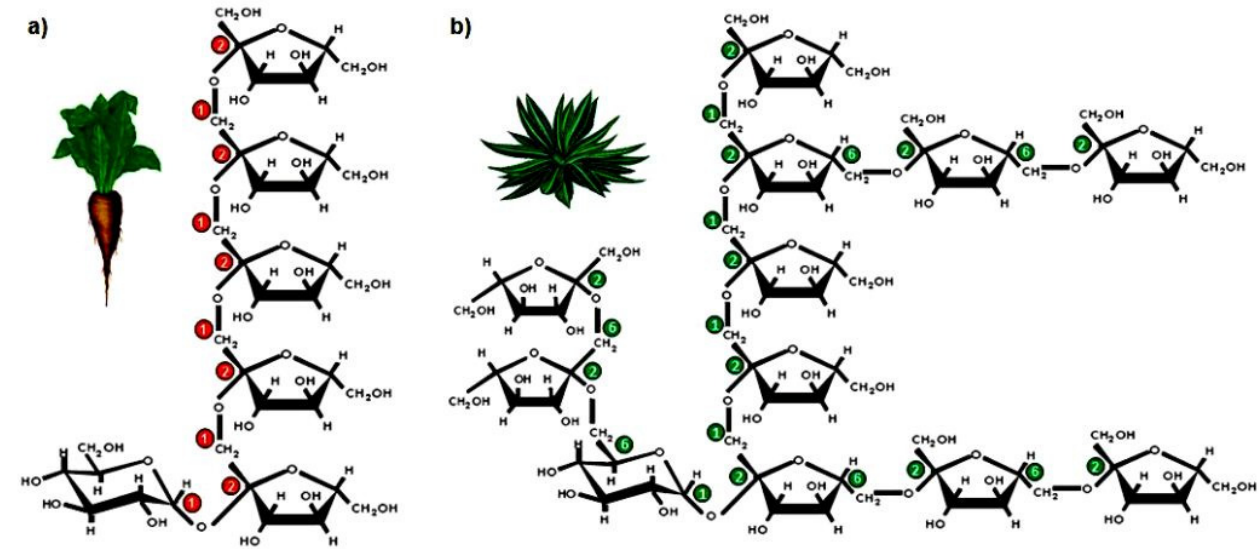

Figure 1. Schematic representation of the main structural differences between a) chicory fructans, "inulins" and b) agave fructans, "agavins".

All fructans are considered prebiotics molecules that serve as a substrate for the gut microbiota [6, 12-15]. A prebiotic is an ingredient selectively fermented by probiotics (bifidobacteria and lactobacilli) that induces specific changes on the composition and/or activity of the gastrointestinal microbiota, conferring benefits upon the host well-being and health in general $[16,17]$. The fermentation of fructans in the colon generates short chain fatty acids (SCFAs). SCFAs formation is an important event since it favors the maintenance and the development of beneficial microbiota as well as the colonic epithelial cells [16]. 


\subsection{Short chain fatty acids (SCFAs)}

The gastrointestinal tract is an extremely complex ecosystem containing about $10^{11} \mathrm{CFU}$ (colony forming units) of bacteria per gram of intestinal content. This large population of bacteria plays a key role in the nutrition and health of the host [18]. The colonic microbiota ferments organic material that cannot be digested otherwise by the host in the upper gut. These include resistant starch, non-digestible carbohydrates (fructans) as well as some proteins and amino acids [19]. The main products of fructans metabolism in the colon are linear SCFAs, mostly acetate $\left(\mathrm{C}_{2: 0}\right)$, propionate $\left(\mathrm{C}_{3: 0}\right)$ and butyrate $\left(\mathrm{C}_{4: 0}\right)$ [19-21] (Figure 2). However, other fermentation products may be lactate, succinate as well as ethanol [6], which are sometimes only intermediates in the global process of carbohydrates fermentation by the microbiota, and are metabolized in varying degrees to SCFAs by interactions and/or collaboration of present bacteria in the ecosystem, so that generally do not accumulate to any significant extent in the colon [22]. Fructans fermentation also produces a few gases as $\mathrm{CO}_{2}, \mathrm{CH}_{4}, \mathrm{H}_{2}$ and additionally heat $[19,23]$. The presence of both, non-digestible carbohydrates and SCFAs in the colon can positively alter the colonic physiology drastically [24]. Various studies on microbial population have shown that SCFAs production is in the order of $\mathrm{C}_{2: 0}>\mathrm{C}_{3: 0}>\mathrm{C}_{4: 0}$ in a molar ratio of approximately 60:20:20 mainly in the proximal and distal colon $[19,25]$. An increased in SCFAs synthesis also creates a more acidic environment in the gut, which is important in vivo in terms of colonization resistance against pathogens $[18,20]$. The production of SCFAs is affected by many factors, including the source of substrate [26], in particular, the chemical composition of the fermentable substrate, the amount of substrate available, its physical form (e.g. particle size, solubility, association with undigestible complexes such as lignin) [27], the bacterial species composition of the microbiota [12], ecological factors (competitive and cooperative interactions between different groups of bacteria) and intestinal transit time [25]. The gut of mice comprises four sections: caecum, proximal, transverse (medial) and distal colon. The caecum and proximal colon are the main sites where fermentation is carried out, given the number of bacteria and the availability of substrate, because as it moves through the intestine toward the distal colon, there is a lower concentration of water as well as a depletion of carbohydrates and increased $\mathrm{pH}$ [22]. SCFAs are rapidly absorbed in the caecum and colon being excreted in the faeces only from $5 \%$ to $10 \%$ of them [24]. The major SCFAs ( $\mathrm{C}_{2: 0}, \mathrm{C}_{3: 0}$ and $\left.\mathrm{C}_{4: 0}\right)$, are absorbed at comparable rates in different regions of the colon. Once absorbed, SCFAs are metabolized at three major sites in the body: 1) cells of the caecum-colonic epithelium that use $\mathrm{C}_{4: 0}$ as a major substrate for maintenance-energy; 2) liver cells that metabolize residual $\mathrm{C}_{4: 0}$ and $\mathrm{C}_{3: 0}$ used for gluconeogenesis and $50 \%$ to $70 \%$ of $\mathrm{C}_{2: 0}$ is also taken up by the liver; and 3) muscle cells that generate energy from the oxidation of residual $\mathrm{C}_{2: 0}$ [3].

\subsubsection{Acetic $\left(C_{2: 0}\right)$, propionic $\left(C_{3: 0}\right)$ and butyric $\left(C_{4: 0}\right)$ acids}

$\mathrm{C}_{2: 0}$ is the principal SCFA produced in the colon, this is readily absorbed and transported to the liver, and therefore is less metabolized in the colon [26]. The presence of acetyl-CoA synthetase in the cytosol of adipose and mammary glands allows the use of $\mathrm{C}_{2: 0}$ for 
lipogenesis once it enters the systemic circulation [24]. $\mathrm{C}_{2: 0}$ is the primary substrate for cholesterol synthesis. In the host, it may be absorbed and utilized by peripheral tissues also [29].

On the other hand, $\mathrm{C}_{3: 0}$ is produced via two main pathways: 1) by fixation of $\mathrm{CO}_{2}$ to form succinate, which is subsequently decarboxylated (the "dicarboxylic acid pathway") and 2) forms lactate and acrylate (the "acrilate pathway") [30]. C3:0 is also a substrate for hepatic gluconeogenesis and it has been reported that this acid inhibits cholesterol synthesis in hepatic tissue [31, 32]. The ratio of $C_{3: 0}$ to $C_{2: 0}$ in the colon is relevant since it lowers cholesterol synthesis coming from the $\mathrm{C}_{2: 0}$ pathway [32].

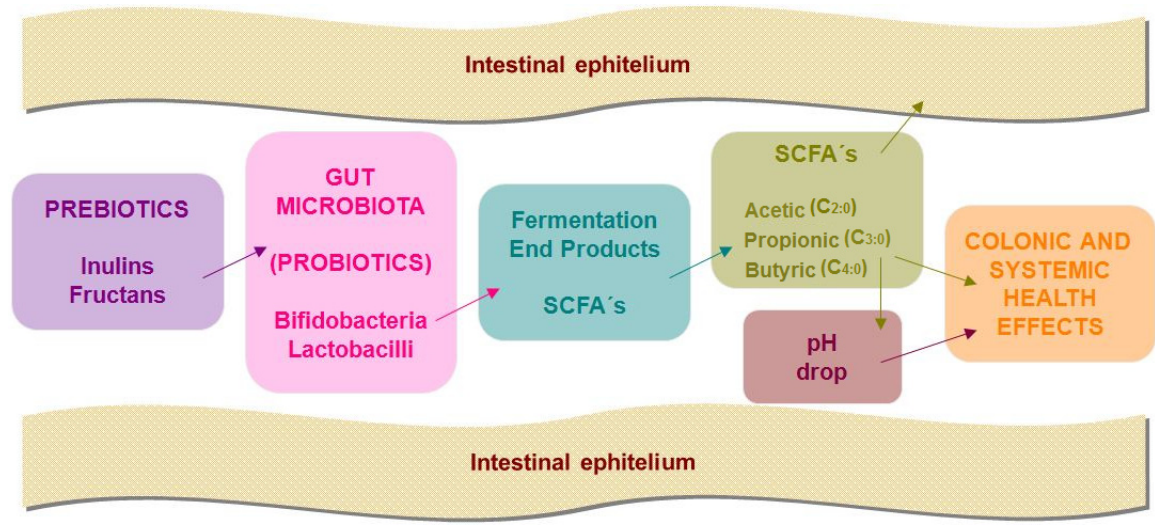

Figure 2. General events taken place in the large intestine. Prebiotics are the specific food for probiotics which ferment them to produce short chain fatty acids (SCFAs) to improve the host health.

Finally, $\mathrm{C}_{4: 0}$ is the preferred fuel by the colonic epithelial cells but also plays a major role in the regulation of cell proliferation and differentiation [19]. It is the most important SCFA in colonocytes metabolism, where $70 \%$ to $90 \%$ of $\mathrm{C}_{4: 0}$ is metabolized by the colonocytes. $\mathrm{C}_{4: 0}$ is used preferentially over $C_{3: 0}$ and $C_{2: 0}$ in a ratio of 90:30:50 [26]. Approximately $95 \%$ of the $C_{4: 0}$ produced by colonic bacteria is transported across the epithelium, but concentrations in portal blood are usually undetectable as a result of a rapid utilization [33]. C4:0 production might also occur through the use of other fermentation products such as $C_{2: 0}$ or lactate that can act as precursors of $\mathrm{C}_{4: 0}$.

\subsubsection{Production of SCFAs in vitro}

In vitro SCFAs production can be measured using pure cultures of selected bacteria species of faecal slurry and some prebiotics (undigestible carbohydrates, for instance).

a. Inulins

Studies in vitro using faecal inocula incubation have shown that different substrates (prebiotics) yield various SCFAs patterns; Van de Wiele et al. [34] compared the fermentation of FOS and inulin in vitro with faecal inoculum, observing that FOS and inulin 
increased the production of SCFAs by about 30\%. This increment in SCFAs production was attributed to an increase mainly in $\mathrm{C}_{3: 0}$ and $\mathrm{C}_{4: 0}$ acids. Where inulin showed a higher production of $\mathrm{C}_{3: 0}$ acid (almost 2-fold) than FOS. The authors concluded that these differences correlated well with the structural differences, FOS has a short DP and inulin a long DP. Stewart et al. [35] analyzed the fermentation of inulins with three different chain lengths (short, medium and long). These researchers found that short inulins were rapidly fermented and produced higher concentrations of $\mathrm{C}_{4: 0}$ compared with other inulins, hence, chain length is an important factor on the fermentation patterns of SCFAs (Table 1). Rycroft et al. [36] performed a comparative evaluation of different prebiotics in vitro, they observed that all the used substrates presented an increased concentration of $\mathrm{C}_{2: 0}$ acid. Inulins generated the highest concentrations of $\mathrm{C}_{3: 0}$ acid, but a mixture of FOS and inulin showed the highest production of $\mathrm{C}_{4: 0}$ acid than the other prebiotics by themselves. The differences in SCFAs patterns in these studies may be also attributed to differences in bacteria species present in the faecal inocula or fermentation process used.

\begin{tabular}{|c|c|c|c|c|c|c|c|c|}
\hline \multirow{2}{*}{ Sample } & \multirow{2}{*}{$\mathrm{DP}_{\text {(mean) }}$} & \multirow{2}{*}{ Time } & \multicolumn{2}{|c|}{$\mathrm{C}_{2: 0^{*}}$} & \multicolumn{2}{|c|}{$\mathrm{C}_{3: 0^{*}}$} & \multicolumn{2}{|c|}{$\mathrm{C}_{4: 0^{*}}$} \\
\hline & & & Mean & SEM & Mean & SEM & Mean & SEM \\
\hline \multirow{2}{*}{ A } & \multirow{2}{*}{$<5$} & $12 \mathrm{~h}$ & $22.3^{a}$ & 0.50 & $5.3^{a}$ & 0.20 & $12.8^{\mathrm{a}}$ & 0.20 \\
\hline & & $24 \mathrm{~h}$ & $16.9^{\mathrm{ab}}$ & 0.10 & 2.1 & 0.10 & $9.1^{\mathrm{a}}$ & 0.30 \\
\hline \multirow{2}{*}{ B } & \multirow{2}{*}{$=4.8$} & $12 \mathrm{~h}$ & $20.2^{\mathrm{ab}}$ & 1.50 & $4.1^{\mathrm{bc}}$ & 0.02 & $10.2^{b}$ & 0.50 \\
\hline & & $24 \mathrm{~h}$ & $15.1^{\mathrm{bd}}$ & 0.03 & 1.8 & 0.20 & $9.0^{\mathrm{a}}$ & 0.40 \\
\hline \multirow{2}{*}{ C } & \multirow{2}{*}{$<10$} & $12 \mathrm{~h}$ & $26.8^{\mathrm{a}}$ & 0.60 & $4.7^{\mathrm{ab}}$ & 0.20 & $12.8^{\mathrm{a}}$ & 0.30 \\
\hline & & $24 \mathrm{~h}$ & $20.9^{c}$ & 0.80 & 2.7 & 0.30 & $9.6^{\mathrm{a}}$ & 0.10 \\
\hline \multirow{2}{*}{ D } & \multirow{2}{*}{$\approx 10$} & $12 \mathrm{~h}$ & $20.0^{\mathrm{ab}}$ & 0.10 & $2.1^{\mathrm{d}}$ & 0.10 & $9.3^{b}$ & 0.20 \\
\hline & & $24 \mathrm{~h}$ & $14.4^{\mathrm{d}}$ & 0.40 & 1.8 & 1.00 & $8.7^{\mathrm{a}}$ & 0.30 \\
\hline \multirow{2}{*}{ E } & \multirow{2}{*}{$>10$} & $12 \mathrm{~h}$ & $19.9^{\mathrm{ab}}$ & 1.30 & $3.6^{c}$ & 0.10 & $9.2^{b}$ & 0.02 \\
\hline & & $24 \mathrm{~h}$ & $25.1^{\mathrm{a}}$ & 0.04 & 3.8 & 0.10 & $9.3^{\mathrm{a}}$ & 0.10 \\
\hline \multirow{2}{*}{$\mathrm{F}$} & \multirow{2}{*}{$>20$} & $12 \mathrm{~h}$ & $14.0^{\mathrm{b}}$ & 2.10 & $0.8^{\mathrm{e}}$ & 0.20 & $5.4^{\mathrm{c}}$ & 0.10 \\
\hline & & $24 \mathrm{~h}$ & $18.7^{a}$ & 0.20 & 2.4 & 0.10 & $6.8^{\mathrm{b}}$ & 0.10 \\
\hline
\end{tabular}

${ }^{*}$ Concentration $\mu \mathrm{mol} / \mathrm{mL}$. Values with different letter within a time point are statistically different from each other $(\mathrm{P}<0.05)$. [35, with modifications].

Table 1. Concentration of acetic $\left(\mathrm{C}_{2: 0)}\right)$, propionic $\left(\mathrm{C}_{3: 0}\right)$ and butyric $\left(\mathrm{C}_{4: 0}\right)$ acids obtained after 12 and $24 \mathrm{~h}$ in vitro fermentation batch with inulins of different chain length.

\section{b. Agave fructans}

Urías-Silvas \& López [37] analyzed the prebiotic potential of fructans extracted from five different species of Agave spp. grown in different regions of Mexico, Dasylirion sp. and commercial inulins, using strains of bifidobacteria and lactobacilli. These researchers found that branched fructans from Dasylirion (DSC) with a DP range from 3 to 20 and A. tequilana from the state of Guanajuato (ATG) with a DP between 3 and 22, stimulated better the growth of both bacteria genera in MRS medium (Figure 3). Moreover, the major SCFAs fermentation product, were acetic, formic and lactic acids, wherein the proportions of the 
acids varied depending on the prebiotic type used by the different bacteria. Figure 4 shows the fermentation products only for the two agave fructans (DSC and ATG) and commercial inulins (RSE and RNE) that better stimulated the growth of bacteria. In general, in figure 4 it can be observed that the branched fructans (agavins) were able to produce more acids than the linear fructans (inulins).

Santiago-García \& López [38] studied the in vitro prebiotic effect of fructans from A. angustifolia of long-DP, short-DP and three combinations of them. The growth rate of bifidobateria and lactobacilli strains with $A$. angustifolia fructans was compared with commercial inulins (Raftiline and Raftilose). The authors observed that agave fructans stimulated the growth of bifidobacteria and lactobacilli more efficiently (2-fold) that commercial inulins, either long- or short-DP. They also reported that short-DP fructans in the mixtures highly influenced the rate of fermentation by probiotc bacteria. In this work, the main fermentation product in all treatments was $\mathrm{C}_{2: 0}$ acid. Moreover, Gomez et al. [39] compared the growth of bifidobacteria and lactobacilli on a complex faecal microbiota in vitro using fructans extracted from A. tequilana Weber var. azul and different commercial inulins. Their results indicated no significant differences among the growth of both bacteria genera with the different fructans used. With regard to the total SCFAs production by agave fructans and inulins was very similar. $\mathrm{C}_{2: 0}$ acid was the most prevalent SCFA in all treatments, only agave fructans and inulin of long-DP produced significantly higher amounts of $C_{3: 0}$, however, there were no significant differences between the different fructans used.
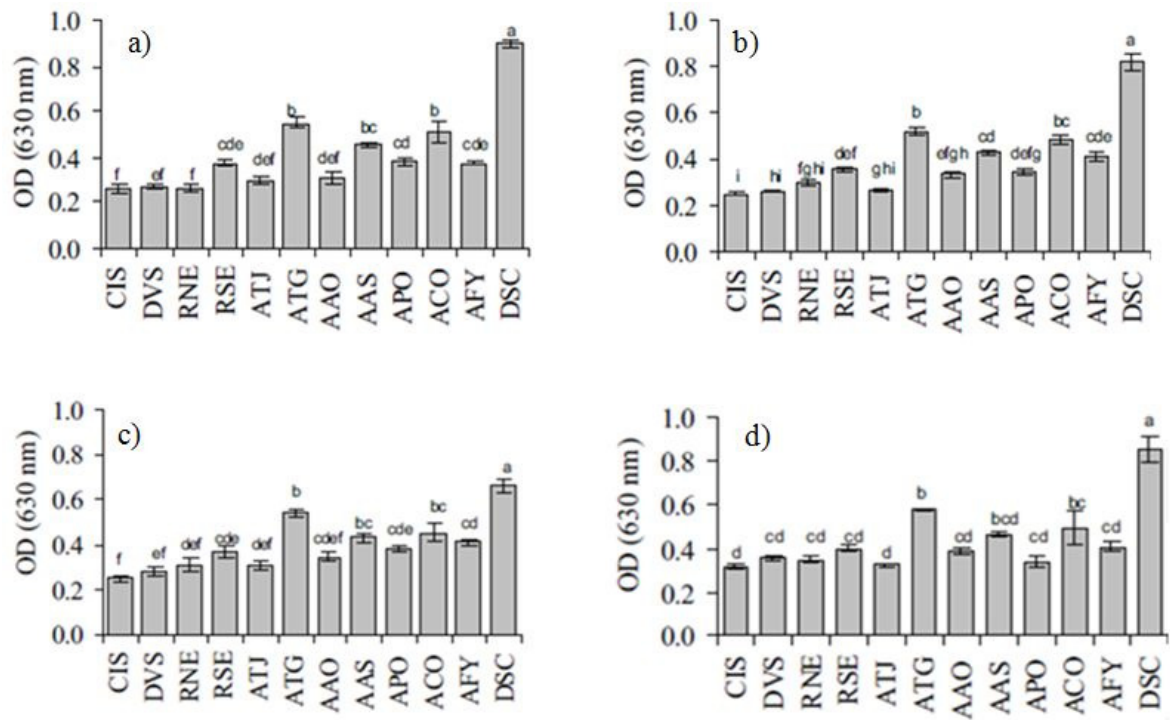

Figure 3. Effect of different fructans on the growth of a) B. adolescentis; b) B. infantis; c) L. paracasei and d) L. rhamnosus incubated anaerobically at $37^{\circ} \mathrm{C}$ in the presence of $10 \mathrm{~g}$ of fructan/L. OD, Optical density; CIS, Cichorium intybus; DVS, Dahlia variabilis; RNE, Raftiline; RSE, Raftilose; ATJ, A. tequilana Jalisco; ATG, A. tequilana Guanajuato; AAO, A. angustifolia Oaxaca; AAS, A. angustifolia Sonora; APO, A. potatorum Oaxaca; ACO, A. cantala Oaxaca; AFY, A. fourcroydes Yucatán; DSC, Dasylirion sp. Chihuahua. 


\subsubsection{Production of SCFAs in vivo}

a. Inulins

Nilsson and Nyman [40] evaluated the formation of SCFAs in the hindgut of rats fed with lactulose, lactitol, FOS and inulins of different DP and solubility. The major acids formed were $\mathrm{C}_{2: 0}, \mathrm{C}_{3: 0}$ and $\mathrm{C}_{4: 0}$. The highest levels of $\mathrm{C}_{3: 0}$ acid were found in caecum and proximal and distal colon of rats fed with inulins, whereas the highest levels of $\mathrm{C}_{4: 0}$ acid were found in caecum and proximal and distal colon of rats fed with FOS. The authors concluded that the DP and solubility of the used prebiotics were of great importance on SCFAs production.
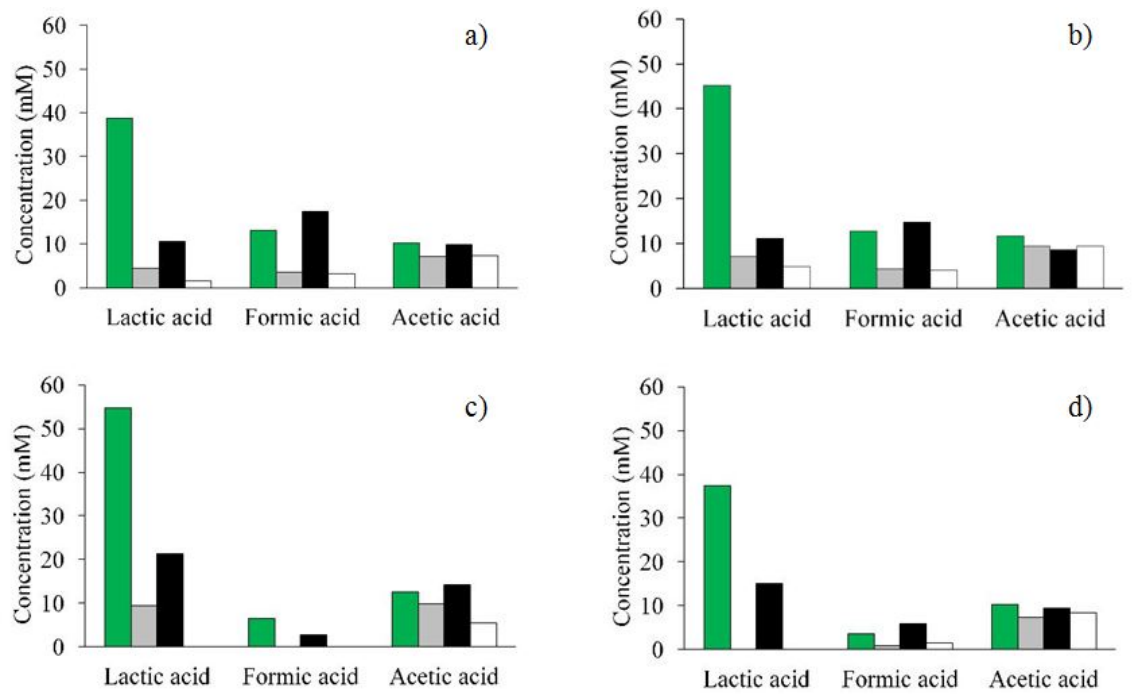

Figure 4. Concentration of short chain fatty acids generated by bifidobacteria and lactobacilli from the fermentation of Dasylirion sp. (DSC; $\square$ ), Raftilose (RSE; $\square$ ), A. tequilana GTO. (ATG; $\mathbf{n}$ ) and Raftiline $(\mathrm{RNE} \square$ ). a) B. adolescentis; b) B. infantis; c) L. paracasei and d) L. rhamnosus.

Similar results were obtained by Licht et al. [41] who fed rats with different dietary carbohydrates. These authors concluded that $\mathrm{C}_{3: 0}$ acid concentrations reached statistical significance in animals fed with inulins, whereas the concentration of $\mathrm{C}_{4: 0}$ acid was significantly higher in animals receiving FOS. Klessen et al. [42] also determined the production of SCFAs in the caecum and colon of germ-free rats associated with contents of human faecal, the rats were fed with inulins of different chain lengths (FOS, inulins and a mixture of FOS-inulins). They observed that FOS produced the greatest amount of $\mathrm{C}_{2: 0}$ acid in the colon of the rats whereas inulins increased the concentration of $\mathrm{C}_{3: 0}$ acid in the caecum of the animals that consumed this diet. Moreover, FOS, inulins and the mixture of FOSinulins increased the amount of $\mathrm{C}_{4: 0}$ acid in the caecum and colon of the rats fed with the mixture regard to animals fed with standard diet. The authors concluded that the type of diet and the fermentation site in the colon affected the concentration of SCFAs (Table 2). In another work, Levrat et al. [43] fed rats with different percentages of inulins (5, 10 and 20\%), 
finding that $C_{2: 0}$ acid production was significantly lower in rats fed with $20 \%$ inulin diet. Moreover, all percentages of inulin increased the levels of $\mathrm{C}_{3: 0}$ acid in the caecum of the rats; the highest concentration was found in animals that consumed the $10 \%$ inulin diet whereas $\mathrm{C}_{4: 0}$ acid concentration was markedly enhanced in all supplemented diets in spite of the inulin percentage used. In another study, the same authors fed rats with $10 \%$ of inulin, they found a higher concentration of $\mathrm{C}_{3: 0}$ acid in the portal vein as well as a significant decrease in plasma cholesterol levels of the rats fed with this diet with regard to animals that consumed the standard diet [44]. On the other hand, a study carried out using obese rats that received a diet supplement with inulin, a two-fold greater $\mathrm{C}_{3: 0}$ concentration in the portal vein and a decrement on triglyceride accumulation in the liver of these animals was observed [45]. A similar result was seen in hamsters fed with different percentages of inulins $(8,12$ and 16\%). Plasma cholesterol and triglyceride concentrations were significantly lower with all the percentages of inulins studied with respect to hamsters fed with the standard diet [46].

\begin{tabular}{|c|c|c|c|c|c|c|}
\hline \multirow{2}{*}{ Acid } & \multirow{2}{*}{ Segment } & \multicolumn{4}{|c|}{ Diet } & \multirow{2}{*}{ Pooled SEM } \\
\hline & & Standard & FOS & Inulin & Mix (FOS-Inulin)² & \\
\hline \multirow{3}{*}{$\mathrm{C}_{2: 0^{1}}$} & Caecum & 49.8 & 55.4 & 45.9 & 51.2 & 1.3 \\
\hline & Colon & 41.1 & $50.8^{*}$ & 42.5 & 46.7 & 1.2 \\
\hline & Faeces & 37.4 & 35.1 & 35.6 & $27.6^{*}$ & 1.3 \\
\hline \multirow{3}{*}{$\mathrm{C}_{3: 0^{1}}$} & Caecum & 21.1 & 22.8 & $32.5^{*}$ & 19.1 & 0.8 \\
\hline & Colon & 18.2 & 17.8 & 21.3 & 16.8 & 0.7 \\
\hline & Faeces & 14.7 & 15.5 & 14.4 & 15.8 & 0.4 \\
\hline \multirow{3}{*}{$\mathrm{C}_{4: 0^{1}}$} & Caecum & 13.4 & $21.3^{*}$ & $25.4^{*}$ & $28.0^{*}$ & 1.3 \\
\hline & Colon & 9.3 & $18.6^{*}$ & $18.1^{*}$ & $22.3^{*}$ & 1.2 \\
\hline & Faeces & 7.1 & 11.4 & $13.6^{*}$ & $15.7^{*}$ & 0.9 \\
\hline
\end{tabular}

Mean values $\mathrm{n}=6 ;{ }^{1}$ Concentrations $[\mu \mathrm{mol} / \mathrm{g}$ wet wt $] ;{ }^{2}$ Mix FOS-Inulin $(1: 1 \mathrm{w} / \mathrm{w})$. Mean values were significantly different from those of the standard diet group: ${ }^{*} \mathrm{P}<0.05$. [42, with modifications].

Table 2. Production of short chain fatty acids in the caecum, colon and faeces in rats associated with human faecal contents and fed with inulins of different chain lengths.

\section{b. Agave fructans}

To date, there are no published reports on the production of SCFAs in vivo using agave fructans of any species. However, the physiological effects of fructans extracted from $A$. tequilana Gto. (ATG) and Dasylirion sp. (DSC) have shown that agave fructans positively impact some lipid metabolic molecules such triglycerides and cholesterol on serum of mice fed with diets supplemented with these types of fructans (Figure 5) they also affect glucose levels [47]. These effects were attributed to the production of $C_{3: 0,}$ which is largely produced through the fermentation of all fructans. 


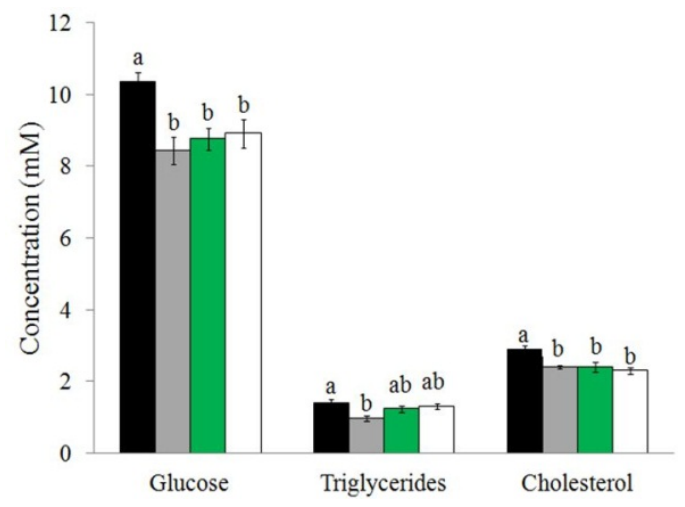

Figure 5. Concentration of glucose, triglycerides and cholesterol in mice after consumption of a standard diet (STD; $\mathbf{\square}$ ) or diet supplemented with fructans: chicory (RSE; $\square$ ); A. tequilana Gto. (ATG; $\square$ ) and Dasylirion sp. (DSC; $\square$ ). Mean values $\mathrm{n}=8$ with their standard errors of the mean for each parameter measured. Mean values with different letters were significantly different $(\mathrm{P} \leq 0.05)$.

In another study with fructans of Dasylirion sp. (DSC) and commercial inulin Raftilose (RSE), García-Pérez [48] reported that the diets supplemented with fructans had a beneficial effect on the concentration of glucose and cholesterol in blood of the portal vein of mice. Glucose concentrations were significantly lowered by 22 and $27 \%$ in mice fed DAS and RSE diets with respect to mice fed a standard diet. Cholesterol concentrations were also reduced by $20 \%$ in animals receiving DSC and $14 \%$ in mice fed RSE diet. However, levels of triglycerides were not significantly modified by any treatment. In this same study, SCFAs were determined only in faeces (Figure 6). In general, mice fed diets supplemented with DSC present higher amount of $\mathrm{C}_{2: 0,} \mathrm{C}_{3: 0}$ and $\mathrm{C}_{4: 0}$ acids in their faeces. Faecal concentrations of SCFAs are not of course the best way to measure the production rates since large proportion of SCFAs is taken up by the colonic mucosa. Nevertheless, faecal levels of SCFAs are a good marker or indicator of the differences on SCFAs taken place in the gut of mice that consumed fructans diets.

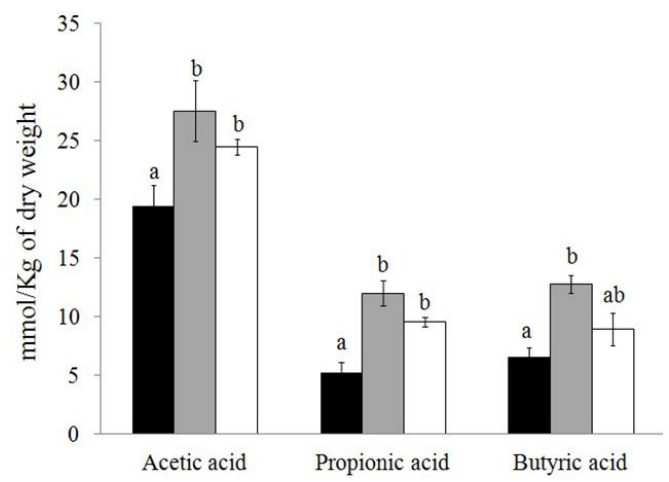

Figure 6. Concentration of SCFAs in faeces of mice fed with a standard diet (STD; $)$ ) or diet supplemented with Raftilose (RSE; $\square$ ) or Dasylirion spp. (DSC; $\square$ ). Mean values n=8 with their standard errors of the mean. Mean values with different letters were significantly different $(\mathrm{P} \leq 0.05)$. 
With all the above, we decided to run an in vivo experiment feeding mice with Agave angustifolia fructans and evaluating the formation of SCFAs in caecum, colonic sections and faeces, as well as the $\mathrm{pH}$ drop in all these areas of the gut.

\section{Materials and methods}

\subsection{Animals and diets}

Twenty-four male C57BL/6J mice of 12 weeks old at the beginning of the experiment were obtained from the animal facilities of CINVESTAV-Zacatenco (Mexico). The mice were housed in a temperature and humidity controlled room with a $12 \mathrm{~h}$ light-dark cycle. They were divided into three groups (eight mice per group) according to diet. Mice were acclimated for 7 days, having free access to a pelleted 5053 standard diet (Laboratory Rodent Diet, USA) and water. During the experimental period (6 weeks), STD mice group were fed with 5053 standard diet, whereas inulins-RNE and agavins-AAO mice groups received a diet prepared by mixing $90 \mathrm{~g}$ of 5053 standard diet with $10 \mathrm{~g}$ of Raftiline or fructans from $A$. angustifolia (AAO). All diets were made by Laboratory Rodent Diet and were available ad libitum to mice.

\subsection{Chemicals}

Agavins were extracted in our laboratory as described by López et al. [10]. Briefly, one hundred grams of milled Agave angustifolia stems were extracted twice with $100 \mathrm{ml}$ of $80 \%$ $\mathrm{v} / \mathrm{v}$ ethanol with continuous shaking for $1 \mathrm{~h}$ at $55^{\circ} \mathrm{C}$. The sample was filtered and the plant material re-extracted with $100 \mathrm{ml}$ of water for $30 \mathrm{~min}$ at $55^{\circ} \mathrm{C}$. The supernatants were mixed; chloroform was used to eliminate the organic fraction. The aqueous phase was concentrated by rotary evaporation under reduced pressure. The sample was dried using a spray dryer and stored in a humidity-free container. RNE were from Beneo Orafti. The average degree polymerization for agavins is 32[11] and for RNE $>23$.

\subsection{Faeces and blood samples}

Faeces collection was performed once a week during the experimental period to evaluate the SCFAs. On day 45, mice were anaesthetized by intra-peritoneal injection of sodium pentobarbital solution. Portal vein blood samples were collected in EDTA tubes; after centrifugation for 10 minutes at 2500 r.p.m., plasma was stored at $-80{ }^{\circ} \mathrm{C}$. The concentration of serum triglycerides, cholesterol and glucose was measured using kits coupling enzymatic reaction and spectrophotometric detection of reaction end-products (BioVision).

\section{4. $\mathrm{pH}$ and SCFAs}

Segments of the caecum and proximal, medial and distal colon were immediately excised. Caecal and colonic contents of each section were collected in tubes and frozen at $-80{ }^{\circ} \mathrm{C}$. The pH measurements were made using a microelectrode (PHR-146, Lazar Research 
Laboratories, Inc.). Analysis of SCFAs was carried out by gas chromatography and flame ionization detection as described by Pietro Femia et al. [49] with some modifications. Briefly, $0.05 \mathrm{~g}$ of caecal and faecal contents were acidified with $0.05 \mathrm{ml}$ of sulfuric acid and SCFAs were extracted by shaking with $0.6 \mathrm{ml}$ of diethyl ether and subsequent centrifugation at 14000 r.p.m. for 30 s. One microliter of the organic phase was injected immediately into the capillary column (Nukol) of the gas chromatograph coupled to a flame ionization detector. The initial temperature was $80^{\circ} \mathrm{C}$ and the final temperature was $200{ }^{\circ} \mathrm{C}$. Nitrogen was used as carrier gas and the quantification of the samples was carried out using calibration curves for $\mathrm{C}_{2: 0}, \mathrm{C}_{3: 0}$ and $\mathrm{C}_{4: 0}$ acids. A standard curve for each acid was done for their quantitation in the samples.

\subsection{Statistical analysis}

Results are expressed as mean values with their standard errors of the mean. Statistical differences between groups were evaluated using one-way ANOVA followed by a Tukey test using GraphPad Prism version 5 for Windows. $\mathrm{P}<0.05$ was regarded as statistically significant.

\section{Results}

\subsection{Feed intake and body weight}

The intake of all mice independently of the diet fed ranged between 3.3 and $4.2 \mathrm{~g} / \mathrm{d}$ with an average of $3.7 \mathrm{~g} / \mathrm{d}$, it is worth to mention that the intake fluctuated weekly throughout the study. The feed intake was $9 \%$ lower for the AAO group compared to the STD and RNE diets. Mice fed with the diet supplemented with RNE ate 10\% more food than even the STD group. Initial body weights ranged from 21.4 to $24.4 \mathrm{~g}$ with final body weights ranging between 24.3 and $25.9 \mathrm{~g}$. No significant differences among all groups were noted in body weight even though mice fed AAO reduced their intake.

\subsection{Production of SCFAs and $\mathrm{pH}$ drop}

The total production of SCFAs was greater for the group of mice fed with AAO in the caecum and proximal and medial colon. However in the distal colon, the production of SCFAs were not significantly different among supplemented diets but it did with the STD $\operatorname{diet}$ (Table 3).

$\mathrm{C}_{2: 0}$ was the most abundant acid formed in the caecum and colon of all mice followed by $\mathrm{C}_{3: 0}$ and $C_{4: 0}$ acid. The concentrations of $C_{2: 0}$ acid were significantly higher in the caecum and the first two sections of the colon (proximal and medial) in mice fed with AAO diet compared to RNE or STD groups. However, in the distal colon there were no significant differences on the production of $\mathrm{C}_{2: 0}$ acid between groups of mice fed fructans (Figure 7a). The higher concentration of $\mathrm{C}_{3: 0}$ acid was found in the caecum of mice fed with AAO diet. This increment was significant with regard to RNE but not for the STD diet. In the proximal and 
medial colon $\mathrm{C}_{3: 0}$ acid production was greater for mice fed $\mathrm{AAO}$, but these enhancements were not significant. Interestingly, in the distal colon of mice fed fructans (AAO and RNE) the enhancement was significantly for the production of $\mathrm{C}_{3: 0}$ acid (Figure $7 \mathrm{~b}$ ). The concentration of $\mathrm{C}_{4: 0}$ acid increased approximately $24 \%$ in the caecum of mice fed with RNE diet. This enhanced was significant with regard to AAO but not for the STD diet. Finally, an increment of $\mathrm{C}_{4: 0}$ acid was observed in the medial and distal colon, this change was significant in mice fed with AAO and RNE diets compared to mice fed with the STD diet (Figure 7c).

SCFAs changes were confirmed when the $\mathrm{pH}$ was measured in all the same samples. The mice fed AAO diet showed a pronounced $\mathrm{pH}$ drop in the caecum and all sections of the colon. The group of mice fed RNE showed significant $\mathrm{pH}$ drop only in the medial and distal colon and the $\mathrm{pH}$ of the mice fed a STD diet did not change significantly in any sections of the gut (Figure 8). The $\mathrm{pH}$ drop changes positively correlated with the total production of SCFAs (Table 3).

\begin{tabular}{|c|c|c|c|c|c|c|}
\hline \multirow{2}{*}{ Section } & \multicolumn{2}{|c|}{ STD $^{*}$} & \multicolumn{2}{|c|}{$\mathbf{R N E}^{*}$} & \multicolumn{2}{|c|}{$\mathbf{A A O}^{*}$} \\
\hline & Mean & SEM & Mean & SEM & Mean & SEM \\
\hline Caecum & $73.93^{a}$ & 1.98 & $70.90^{\mathrm{a}}$ & 2.08 & $83.48^{\mathrm{b}}$ & 1.54 \\
\hline Proximal colon & $71.98^{\mathrm{a}}$ & 2.11 & $76.93^{a}$ & 2.62 & $106.92^{b}$ & 4.61 \\
\hline Medial colon & $51.44^{\mathrm{a}}$ & 1.25 & $64.26^{\mathrm{b}}$ & 2.59 & $107.25^{b}$ & 2.41 \\
\hline Distal colon & $28.58^{a}$ & 0.86 & $49.65^{b}$ & 2.91 & $66.84^{\mathrm{b}}$ & 2.97 \\
\hline
\end{tabular}

${ }^{*}[\mathrm{mmol} / \mathrm{Kg}$ of fresh weight $]$. Mean values $\mathrm{n}=8$ with their standard errors of the mean. ${ }^{\mathrm{a}, \mathrm{b}}$ Mean values with unlike superscript letters were significantly different $(\mathrm{P} \leq 0.05)$.

Table 3. Concentration of total short chain fatty acids production in the caecum and the three sections of the colon in mice fed a standard (STD) diet or diet supplemented with Raftiline (RNE-inulin) or Agave angustifolia Oax. (AAO-agavins). 

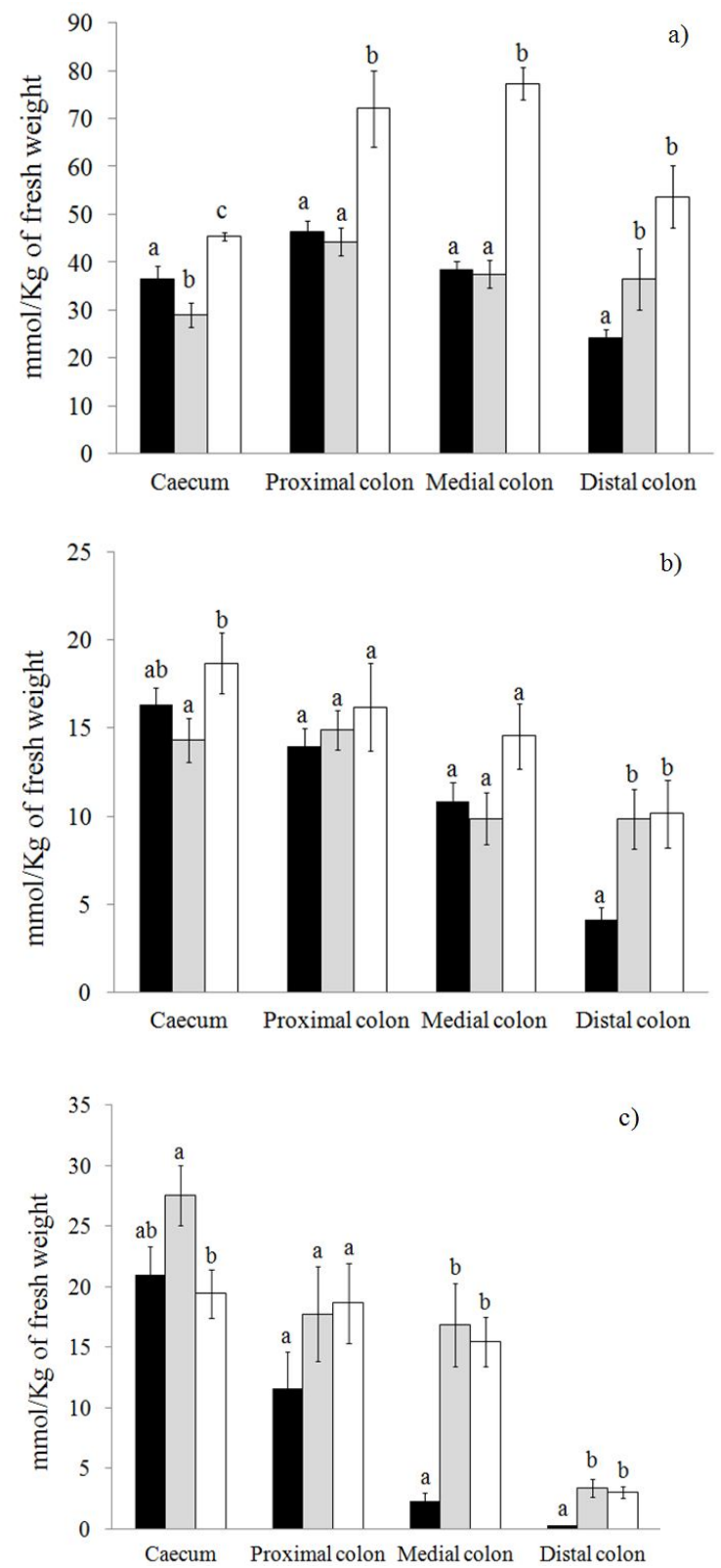

Figure 7. Concentrations of SCFAs in the caecum and the three sections of the colon of mice fed with a standard diet (STD; $\square$ ) and supplemented diets containing Raftiline (RNE; $\square$ ) and A. angustifolia Oax. (AAO; $\square$ ). A) Acetic acid ( $2: 0)$; B) Propionic acid ( $\left.\mathrm{C}_{3: 0}\right)$; and C) Butyric acid ( $\left.\mathrm{C}_{4: 0}\right)$. Mean values $\mathrm{n}=8$ with their standard errors of the mean for each parameter measured. Mean values with different letters were significantly different $(\mathrm{P} \leq 0.05)$. 


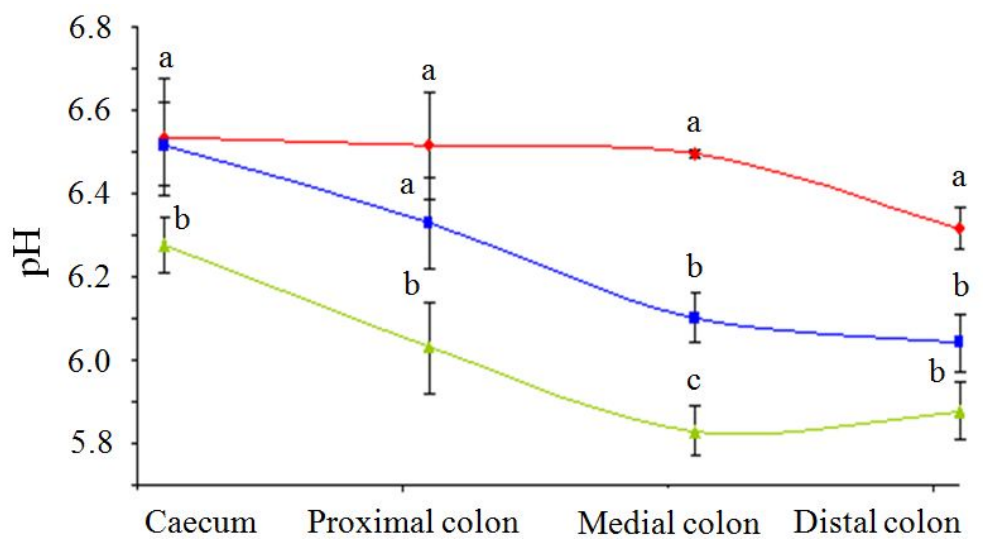

Figure 8. $\mathrm{pH}$ values in the caecum and the three sections of the colon of mice fed a standard diet (STD; ) or diet supplemented with Raftiline (RNE; - ) or A. angustifolia Oax. (AAO; ). Mean values n=8 with their standard errors of the mean. Mean values with different letters were significantly different $(\mathrm{P} \leq 0.05)$.

\subsection{SCFAs in the faeces}

The analyses of SCFAs in the collected faeces showed that $C_{2: 0}$ acid was again the most abundant acid in the faeces of all mice followed by $\mathrm{C}_{3: 0}$ and $\mathrm{C}_{4: 0}$ acids. However, the amounts of $\mathrm{C}_{2: 0}$ and $\mathrm{C}_{3: 0}$ acids excreted in the faeces were not affected significantly by any dietary treatment. Surprisingly, only the mice fed with agavins (AAO) or inulin (RNE) diets, showed a significant increment on the amount of $\mathrm{C}_{4: 0}$ acid compared with the STD diet (Figure 9).

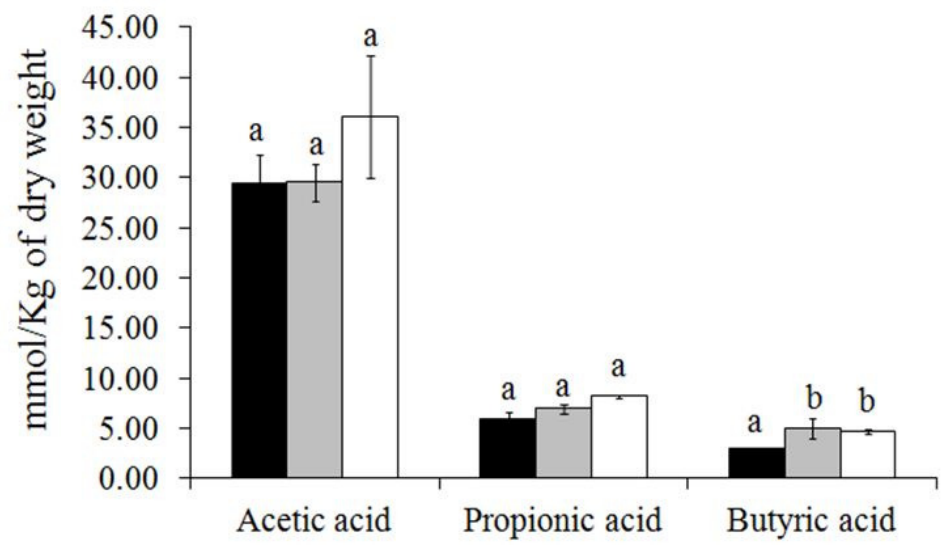

Figure 9. Concentration of acetic $\left(\mathrm{C}_{2: 0}\right)$, propionic $\left(\mathrm{C}_{3: 0}\right)$ and butyric $\left(\mathrm{C}_{4: 0}\right)$ acids excreted in the faeces of mice fed a standard diet (STD; $\square$ ) or diet supplemented with Raftiline (RNE; $\square$ ) or A. angustifolia Oax. $(\mathrm{AAO} ; \square)$. Mean values $\mathrm{n}=8$ with their standard errors of the mean. Mean values with different letters were significantly different $(\mathrm{P} \leq 0.05)$. 


\subsection{Plasma glucose, triglyceride and cholesterol}

Besides SCFAs some other physiological parameters were determined in the plasma of all mice groups, among them glucose, triglycerides and cholesterol. Glucose concentrations of mice fed AAO and RNE diets were significantly lowered by $12 \%$ and $17 \%$ respectively when compared to the STD diet. On the other hand, triglycerides concentrations of the supplemented groups compared with the STD were reduced by $37 \%$ and $38 \%$ in mice fed AAO and RNE diets, respectively. A reduction of cholesterol concentrations by $36 \%$ and 38 $\%$ in animals receiving AAO and RNE diets was also observed vs STD diet (Table 4).

\begin{tabular}{lllllllll}
\hline \multirow{2}{*}{ Diet } & \multicolumn{2}{c}{ Glucose $(\mathbf{m M})$} & & \multicolumn{2}{c}{ Triglyceride $(\mathrm{mM})$} & & \multicolumn{2}{c}{ Cholesterol $(\mathrm{mM})$} \\
\cline { 2 - 3 } & Mean & SEM & & Mean & SEM & & Mean & SEM \\
\hline STD & $6.690^{\mathrm{a}}$ & 0.25 & & $3.070^{\mathrm{a}}$ & 0.09 & & $3.087^{\mathrm{a}}$ & 0.10 \\
RNE & $5.932^{\mathrm{b}}$ & 0.27 & & $2.233^{\mathrm{b}}$ & 0.27 & & $1.876^{\mathrm{b}}$ & 0.14 \\
AAO & $5.857^{\mathrm{b}}$ & 0.31 & & $2.378^{\mathrm{b}}$ & 0.18 & & $1.756^{\mathrm{b}}$ & 0.09 \\
\hline
\end{tabular}

(Mean values $\mathrm{n}=8$ with their standard errors of the mean for each parameter measured) ${ }^{a, b}$ Mean values with unlike superscript letters were significantly different $(\mathrm{P} \leq 0.05)$.

Table 4. Glucose, triglycerides and cholesterol levels in plasma of mice fed with a standard (STD) diet or diet supplemented with Raftiline (RNE) and A. angustifolia Oax. (AAO).

\section{Discussion}

The determination of the production of $\mathrm{C}_{2: 0}, \mathrm{C}_{3: 0}$ and $\mathrm{C}_{4: 0}$ acids in the caecum, proximal, medial and distal colon of mice fed with different diets, was performed with the aids to evaluate the profiles of these acids throughout the caecum, large intestine and faeces of mice, and also to be able to establish the main sites of fermentation of inulins such Raftiline (RNE) and fructans extracted from A. Angustifolia (AAO) supplemented in the diets. These objectives basically arise from the knowledge on the structural differences between the two fructans types. Raftiline is an inulin type fructan with an average DP of 25 and it is know that its structure is completely linear, therefore containing a terminal glucose molecule. On the other hand, $A$. angustifolia fructans have an average DP of 32, with molecular structures very complex, they are highly branched and present a terminal glucose molecule (graminans) or internal glucose (agavins) [11]. Many reports have established that the structure of undigested carbohydrates and the microbiota present in an ecosystem are determining factors that control fermentation in the gut [50]. It is also know that the profiles of the production and distribution of SCFAs in the gut are influenced not only by the type of consumed carbohydrates, but also by the place where fermentation of those carbohydrates takes place, essentially in the caecum in mice and in the upper colon in humans, but the type of substrate may also affect the site of fermentation [51]. Previous reports mentioned that high DP fructans are fermented more slowly in the caecum and proximal colon, thus reaching the distal colon almost unchanged [6,34], but bacteria present in this section produce mainly $\mathrm{C}_{4: 0}$ acid as the end product of such fermentation [51]. In the present work, inulins were fermented poorly in the caecum and proximal colon but an increment was 
observed on the concentration of $\mathrm{C}_{4: 0}$ acid in the distal colon, which agrees well with previous reports. However, mice fed with agave fructans (AAO) produced greater amounts of SCFAs in the caecum and proximal and medial colon than those mice fed with inulins (RNE), suggesting that AAO fructans were easily fermentable, independently of the their high DP, therefore, the difference might be due to the presence of branches in the agave fructans, which could make the molecule more accessible to enzymes (fructosyltransferases), in other words, there are more terminal fructose available for the fructosyltransferases of bacteria. According to the production of SCFAs, proximal and medial colon, were the main sites where fermentation of $A$. angustifolia fructans was carried out. In general, an increment was observed in the production of $\mathrm{C}_{3: 0}$ and $\mathrm{C}_{4: 0}$ acids in the distal colon of mice that received diets supplemented with fructans. On the other hand, total SCFAs and individual SCFAs concentrations in the different sections of the colon are very important since they have been associated with many diseases of the colon, especially with colon cancer and gastrointestinal disorders. Therefore, increased SCFAs production and a greater delivery of them distally, especially $\mathrm{C}_{4: 0}$ acid, may have an important role in preventing some of these diseases and other metabolic problems. Moreover, $C_{3: 0}$ acid has been reported to have a positive metabolic effect, through the inhibition of hepatic cholesterol synthesis from $\mathrm{C}_{2: 0}$ acid [32]. Interestingly, a significant decrease in plasma triglycerides and cholesterol levels of animals fed with fructans was observed in this work. Finally, the mice that consumed agave fructans showed the more pronounced drop on $\mathrm{pH}$ in the caecum and the three sections of the colon, which creates a more acid environment which is highly beneficial for the grow of bacteria such as bifidobacteria and/or lactobacilli but is detrimental for the growth of potentially pathogenic species $[17,18]$.

As a general conclusion, we can mention that the supplementation of diets with inulins or agavins altered the large intestine environment by increasing the amounts of SCFAs and lowering the $\mathrm{pH}$ in the colon, consequently reducing few health risks. Finally, we would like to close this work saying that these SCFAs had a positive effect on the host lipid metabolism, since they decreased the levels of triglycerides, cholesterol and glucose in blood of mice fed with supplemented diets.

Based on all the previous data, agave fructans may offer a good prebiotic potential, opening new and excited alternatives as food supplements. Even do, further research is definitely needed on specific health problems and should be performed using supplemented diets with agavins of different structures as well as different mixtures and concentrations, because more knowledge is needed on health issues such obesity, diabetes, colon cancer and in general, gut associated risks that might be improved with this type of ingredients.

\section{Author details}

Alicia Huazano-García and Mercedes G. López

Departamento de Biotecnología y Bioquímica,

Centro de Investigación y de Estudios Avanzados del IPN, México 


\section{Acknowledgement}

Alicia Huazano-García thanks the Consejo Nacional de Ciencia y Tecnología (CONACYT) for her scholarship and also thanks M.S. Patricia Santiago for the agave fructans sample.

\section{References}

[1] Cairns A., Pollock C., Gallagher J., Harrison J. Fructans: Synthesis and Regulation. Leegood R., Sharkey T., Caemmerer S. von (eds) Photosynthesis: Physiology and Metabolism. Kluwer Academic Publishers; 2000. p 301-320.

[2] Niness K. Inulin and Oligofructose: What are They? The Journal of Nutrition 1999; 129(7) 1402S-1406.

[3] Van Loo J., Coussement P., De Leenheer L., Hoebregs H., Smits G. On the Presence of Inulin and Oligofructose as Natural Ingredients in the Western Diet. Critical Reviews in Food Science and Nutrition 1995; 35(6) 525-552.

[4] Ritsema T., Smeekens S. Engineering Fructan Metabolism in Plants. Journal of Plant Physiology 2003; 160(7) 811-820.

[5] Roberfroid M. Prebiotics: The Concept Revisited. The Journal of Nutrition 2007; 137(3) 830S-837.

[6] Roberfroid M., Van Loo J., Gibson G. The Bifidogenic Nature of Chicory Inulin and its Hydrolysis Products. The Journal of Nutrition 1998; 128(1) 11-19.

[7] Good-Avila S., Souza V., Gaut B., Eguiarte L. Timing and Rate of Speciation in Agave (Agavaceae). Proceedings of the National Academy of Sciences of the United States of America 2006;103(24) 9124-9129.

[8] Eguiarte L., Souza V., Silva-Montellano A. Evolución de la Familia Agavaceae: Filogenia, Biología Reproductiva y Genética de Poblaciones. Bolletin de la Sociedad Botánica de México 2000; 66 131-150.

[9] Gentry H. Agaves of continental North America. The University of Arizona Press; 1998.

[10] López M., Mancilla-Margalli N., Mendoza-Díaz G. Molecular Structures of Fructans from Agave tequilana Weber var. azul. Journal of Agricultural and Food Chemistry 2003; 51(27) 7835-7840.

[11] Mancilla-Margalli N., López G. Water-soluble Carbohydrates and Fructan Structure Patterns from Agave and Dasylirion Species. Journal of Agricultural and Food Chemistry 2006; 54(20) 7832-7839.

[12] Roberfroid M. Introducing Inulin Type Fructans. British Journal of Nutrition 2005;93(1) 13S-25.

[13] Roberfroid M. Prebiotics and Probiotics: Are they Functional Foods? The American Journal of Clinical Nutrition 2000; 71(1) 1682S-1687.

[14] Kolida S., Gibson G. Prebiotic Capacity of Inulin-type Fructans. The Journal of Nutrition 2007; 137(11) 2503S-2506.

[15] López M., Urías-Silvas J. Agave Fructans as Prebiotics. Norio S., Noureddine B., Shuichi O. (eds) Recent Advances in Fructooligosaccharides Research. Research Signpost; 2007. p 1-14. 
[16] Gibson G., Probert H., Van Loo J., Rastall R., Roberfroid M. Dietary Modulation of the Human Colonic Microbiota: Updating the Concept of Prebiotics. Nutrition Research Reviews 2004; 17(2) 259-275.

[17] Gibson G., Roberfroid M. Dietary modulation of the human colonic microbiota: introducing the concept of prebiotics. The Journal of Nutrition 1995; 125(6) 1401-1412.

[18] Roberfroid M. Fructo-oligosaccharide Malabsorption: Benefit for Gastrointestinal Functions. Current Opinion in Gastroenterology 2000; 16(2) 173-177.

[19] Topping D., Clifton P. Short-chain Fatty Acids and Human Colonic Function: Roles of Resistant Starch and Nonstarch Polysaccharides. Physiological Reviews 2001; 81(3) 1031-1063.

[20] Gibson G. Dietary Modulation of the Human Gut Microflora Using the Prebiotics Oligofructose and Inulin. The Journal of Nutrition 1999; 129(7) 1438S-1441.

[21] Cummings J., Macfarlane G. The Control and Consequences of Bacterial Fermentation in the Human Colon. Journal of Applied Bacteriology 1991; 70(6) 443-459.

[22] Bernalier A., Dore J., Durand M. Biochemistry of fermentation. Gibson G., Roberfroid M. (eds) Colonic Microbiota, Nutrition and Health. Dordrecht:Kluwer Academic Publishers; 1999. p 37-53.

[23] Flamm G., Glinsmann W., Kritchevsky D., Prosky L., Roberfroid M. Inulin and Oligofructose as Dietary Fiber: A Review of Evidence. Critical Reviews in Food Science and Nutrition 2001; 41(5) 353;362.

[24] Wong J., De Souza R., Kendall C., Emam A., Jenkins D. Colonic Health: Fermentation and Short Chain Fatty Acids. Journal of Clinical Gastroenterology 2006; 40(3) 235-243.

[25] Cummings J., Roberfroid M., Andersson H., Barth C., Ferro-Luzzi A., Ghoos Y., Gibney M., Hermonsen K., James W., Korver O. A New Look at Dietary Carbohydrate: Chemistry, Physiology and Health. European Journal of Clinical Nutrition 1997; 51(7) 417-423.

[26] Cook S., Sellin J. Short Chain Fatty Acids in Health and Disease. Alimentary Pharmacology and Therapeutics 1998; 12(6) 499-507.

[27] Macfarlane G., Macfarlane S. Models for Intestinal Fermentation: Association between Food Components, Delivery Systems, Bioavailability and Functional Interactions in the Gut. Current Opinion in Biotechnology 2007; 18(2) 156-162.

[28] Zeng J., Tan Z. Metabolic Homeostasis and Colonic Health: The Critical Role of Short Chain Fatty Acids. Current Nutrition and Food Science 2010; 6(3) 209-222.

[29] Pomare E., Branch W., Cummings J. Carbohydrate Fermentation in the Human Colon and its Relation to Acetate Concentrations in Venous Blood. The Journal of Clinical Investigation 1985; 75(5) 1448-1454.

[30] Cummings J. Short Chain Fatty Acids in the Human Colon. GUT 1981; 22(9) 763-779.

[31] Venter C., Vorster H., Cummings J. Effects of Dietary Propionate on Carbohydrate and Lipid Metabolism in healthy volunteers. The American Journal of Gastroenterology 1990; 85(5) 549-553.

[32] Cheng H., Lai M. Fermentation of resistant rice starch produces propionate reducing serum and hepatic Cholesterol in Rats. The Journal of Nutrition 2000; 130(8) 1991-1995. 
[33] Pryde S., Duncan S., Hold G., Stewart C., Flint H. The Microbiology of Butyrate Formation in the Human Colon. FEMS Microbiology Letters 2002; 217(2) 133-139.

[34] Van de Wiele T., Boon N., Possemiers S., Jacobs H., Verstraete W. Inulin-type Fructans of Longer Degree of Polymerization Exert More Pronounced in vitro Prebiotic Effects. Journal of Applied Microbiology 2007; 102(2) 452-460.

[35] Stewart M., Timm D., Slavin J. Fructooligosaccharides Exhibit More Rapid Fermentation than Long-chain Inulin in an vitro fermentation system. Nutrition Research 2008; 28(5) 329-334.

[36] Rycroft C., Jones M., Gibson G., Rastall R. A Comparative in vitro Evaluation of the Fermentation Properties of Prebiotic Oligosaccharides. Journal of Applied Microbiology 2001; 91(5) 878-887.

[37] Urías-Silvas J., López M. Agave spp. and Dasylirion sp. Fructans as a Potential Novel Source of Prebiotics. Dynamic Biochemistry, Process Biotechnology and Molecular Biology 2009; 3(1) 59-64.

[38] Santiago-García P., López M. Prebiotic Effect of Agave Fructans and Mixtures of Different Degrees of Polymerization from Agave angustifolia Haw. Dynamic Biochemistry, Process Biotechnology and Molecular Biology 2009; 3(1) 52-58.

[39] Gomez E., Tuohy K., Gibson G., Klinder A., Costabile A. In vitro Evaluation of the Fermentation Properties and Potential Prebiotic Activity of Agave Fructans. Journal of Applied Microbiology 2010; 108(6) 1859-2228.

[40] Nilsson U., Nyman M. Short-chain Fatty Acid Formation in the Hindgut of Rats Fed Oligosaccharides Varying in Monomeric Composition, Degree of Polymerization and Solubility. British Journal of Nutrition 2005; 94(5) 705-713.

[41] Licht T., Hansen M., Poulsen M.,Dragsted L. Dietary Carbohydrate Source Influences Molecular Fingerprints of the Rat Faecal Microbiota. BMC Microbiology 2006; 6(1) 98107.

[42] Klessen B., Hartmann L., Blaut M. Oligofructose and Long-chain Inulin: Influence on the Gut Microbial Ecology of Rats Associated with a Human Faecal Flora. British Journal of Nutrition 2001; 86(2) 291-300.

[43] Levrat M., Remesy C., Demigne C. High Propionic Acid Fermentations and Mineral Accumulation in the Cecum of Rats Adapted to Different Levels of Inulin. The Journal of Nutrition 1991; 121(11) 1730-1737.

[44] Levrat M., Favier M., Moundras C., Remesy C., Demigne C., Morand C. Role of Dietary Propionic Acid and Bile Acid Excretion in the Hypocholesterolemic Effects of Oligosaccharides in Rats. The Journal of Nutrition 1994; 124(4) 531-538

[45] Daubioul C., Rousseau N., Demeure R., Gallez B., Taper H., Declerck B., Delzenne N. Dietary Fructans, but not Cellulose, Decrease Triglyceride Accumulation in the Liver of Obese Zucker fa/fa Rats. The Journal of Nutrition 2002; 132(5) 967-973.

[46] Trautwein E., Rieckhoff D., Erbersdobler H. Dietary Inulin Lower Plasma Cholesterol and Triacylglycerol and Alters Biliary Bile Acid Profile in Hamsters. The Journal of Nutrition 1998; 128(11) 1937-1943. 
[47] Urías-Silvas J., Cani P., Delmee E., Neyrinck A., López M., Delzenne N. Physiological Effects of Dietary Fructans Extracted from Agave tequilana Gto. and Dasylirion spp. British Journal of Nutrition 2008; 99(2) 254-261.

[48] García-Pérez M. Efecto de los Fructanos de Dasylirion sp. en la Secreción de Grelina y GLP-1 en Ratones. MS thesis. CINVESTAV-Irapuato; 2008.

[49] Pietro F., Luceri C., Dolara P., Giannini A., Biggeri A., Salvadori M., Clune Y., Collins K., Paglierani M., Cademi G. Antitumorigenic Activity of the Inulin Enriched with Oligofructose in Combination with the Probiotics Lactobacillus rhamnosus and Bifidobacterium lactis on Azoximethane-induced Colon Carcinogenesis in Rats. Carcinogenesis 2002; 23(11) 1953-1960.

[50] Henningsson A., Björck I., Nyman G. Combinations of Indigestible Carbohydrates Affect Short-chain Fatty Acid Formation in the Hindgut of Rats. The Journal of Nutrition 2002; 132(10) 3098-3104.

[51] Hughes R., Rowland I. Stimulation of Apoptosis by Two Prebiotic Chicory Fructans in the Rat Colon. Carcinogenesis 2000; 22(1) 43-47. 